\title{
ARTIGOS
}

\author{
Submetido 22.05.2020. Aprovado 19.04.2021
}

Avaliado pelo sistema double-blind review process. Editor Científico: Marcelo Vinhal Nepomuceno

Versão traduzida | DOI: http://dx.doi.org/10.1590/S0034-759020220103x

\section{DISTÂNCIA PSICOLÓGICA NO MARKETING DE PRODUTOS NOSTÁLGICOS PARA COMUNIDADES EM DIÁSPORA: O CASO VENEZUELANO}

\author{
Psychological distance in the diaspora marketing of nostalgic products: A Venezuelan case \\ Distancia psicológica en el marketing de productos nostálgicos para la diáspora: Caso venezolano
}

\begin{abstract}
Walter Palomino-Tamayo ${ }^{1}$ | wpalomino@esan.edu.pe | ORCID: 0000-0002-1140-7362
Maria Christina Saksanian ${ }^{1}$ | csaksanian@esan.edu.pe | ORCID: 0000-0003-1327-7554

Otto Regalado-Pezúa1 | oregalado@esan.edu.pe | ORCID: 0ooo-0001-6196-1479
\end{abstract}

1Universidad ESAN, Marketing Department, Lima, Peru

\section{RESUMO}

Esta primeira revisão sistemática da literatura sobre marketing de diáspora revela que os emergentes estudos têm por principal foco as oportunidades relacionadas ao comércio, turismo e a aculturação de pessoas em diáspora originárias de diversos países com idiomas diferentes em relação a apenas um país anfitrião. Esta pesquisa contribui para uma maior compreensão do comportamento de compra de comunidades em diáspora, especificamente em relação a produtos e serviços nostálgicos, usando a Teoria do Nível de Interpretação e considerando o caso da comunidade venezuelana em diáspora no contexto internacional mais amplo de cinco países anfitriões: Colômbia, Peru, Chile, Equador e Panamá. Outra contribuição do estudo é o uso de métricas e-WOM derivadas de postagens de publicidade no Instagram. Os resultados mostram que consumidores em diáspora vivendo em países com níveis mais elevados de individualismo, menor masculinidade e maior distância geográfica de sua terra natal, tendem a apresentar maior consumo de produtos nostálgicos.

PALAVRAS CHAVE | Marketing de diáspora, e-WOM, dimensões culturais, produtos nostálgicos, teoria do nível de interpretação.

\section{ABSTRACT}

With this first systematic review of specific literature about diaspora marketing, it was found that this emerging literature focuses mainly on opportunities related to trade, tourism, and the acculturation between countries with different languages in only one host country. This research contributes toward a greater understanding of diaspora buying behavior using the construal level theory, specifically regarding the purchase of nostalgic products and services, examining the case of Venezuelan diaspora in the broader international context of five host countries: Colombia, Peru, Chile, Ecuador, and Panama Another contribution is the use of e-WOM metrics derived from advertising posts on Instagram. The results show that diaspora consumers in host countries that have higher levels of individualism, less masculinity, and are further geographically from their homeland seek to consume greater amounts of nostalgic products.

KEYWORDS I Diaspora marketing, e-WOM, cultural dimensions, nostalgic products, construal level theory.

\section{RESUMEN}

A través de esta primera revisión sistemática de la literatura específica del marketing de la diáspora, se encontró que ésta literatura emergente está enfocada en las oportunidades de comercio, turismo y aculturación entre personas de países con diferentes idiomas en un solo país anfitrión. Esta investigación contribuye a comprender el comportamiento de compra de la diáspora, específicamente con respecto a productos y servicios nostálgicos, en un contexto internacional más amplio considerando cinco países anfitriones: Colombia, Perú, Chile, Ecuadory Panamá, y utilizando la teoría del nivel de conceptualización. Otra contribución es la utilización de las métricas e-WOM derivadas de publicaciones publicitarias en Instagram. Los resultados muestran que los consumidores de la diáspora de los países anfitriones con una mayor cultura individualista, una menor masculinidad y una mayor distancia geográfica de su tierra natal prefieren el consumo de productos nostálgicos.

PALABRAS CLAVE I Marketing de la diáspora, e-WOM, dimensiones culturales, productos nostálgicos, teoría del nivel de conceptualización. 


\section{INTRODUÇÃO}

O fluxo de pessoas entre diferentes países é um fenômeno antigo que tem atraído a atenção global, particularmente pelo grande aumento no número de pessoas que deixam seu país natal para fixar residência em outro. Nas últimas três décadas ou mais, o mundo testemunhou esse movimento em um volume sem precedentes. Estatísticas sobre migração global mostram que em 2018, 258 milhões de pessoas residiam em um país diferente de seu país de nascimento, um aumento de 49,1\% em relação a 2000 e $153 \%$ em relação a 1980 (Vidal \& Tjaden, 2018). Esse fenômeno, conhecido como “diáspora”, é definido por Safran (conforme citado em Tambiah, 2017, p. 169, tradução nossa) como "comunidades minoritárias expatriadas que nutrem uma nostalgia ou fantasia sobre seu país natal".

O termo "diáspora" foi usado pela primeira vez por volta de 250 a.C., quando a Bíblia Hebraica foi traduzida para o grego. Essa tradução, a Septuaginta, usava o verbo diaspeirein e o substantivo diasporá para se referir à condição de agonia espiritual dos judeus quando banidos pela ira de Deus. Atualmente, vários termos diferentes como "imigrante”, “comunidade étnica”, “refugiado”, “exilado" e "comunidade no exterior”, compartilham de um significado similar (Tambiah, 2017).

Desde 2014, a Venezuela tem experimentado uma grande onda de emigração. Em abril de 2019, mais de 1,2 milhões de venezuelanos viviam na Colômbia e 728.000 no Peru (as duas maiores concentrações dessa diáspora na região), seguidos pelo Chile, Equador e Panamá com 288.000, 263.000 e 94.00o venezuelanos, respectivamente (R4V, 2019). Esse é o maior êxodo migratório da história da América Latina (AL), representando também uma oportunidade para estudos no campo do marketing de diáspora.

A emigração de venezuelanos ocorre em meio a restrições legais e políticas no país. Em 2015, os acordos de integração regional entre as nações mencionadas acima desobrigavam a solicitação de vistos ou a apresentação de passaportes (Comunidade Andina e Mercosul). Essa situação mudou em agosto de 2017, quando a Venezuela foi suspensa do Mercosul sob a acusação de que seu governo violara a "cláusula democrática" do acordo ( RVV $^{2}$ 2019) e perdeu os benefícios relacionados a imigração. Assim, a partir daquele ano cada país determinou sua própria política de imigração para com a Venezuela. O Panamá foi o primeiro país que, em outubro de 2017 , passou a solicitar que os venezuelanos apresentassem passaporte e visto. Peru, Chile e Equador implementaram requisitos de passaporte e visto em 2019. A Colômbia autorizava apenas entradas temporárias, sempre com passaporte. Por outro lado, os venezuelanos relatavam dificuldades em obter um passaporte em seu país, dado o alto custo e a burocracia. Ainda, antes de 2017, a maioria dos imigrantes venezuelanos entrava ilegalmente na Colômbia, Peru e Equador, sendo que esses países implementaram políticas de regularização com autorizações temporárias que permitiam aos venezuelanos trabalhar e ter acesso a saúde e educação primária para suas crianças. Já as políticas atualmente implementadas desencorajam a migração legal, e um visto humanitário é a única rota legal disponível para os venezuelanos - mesmo que muitos pedidos desse tipo de visto não estão sendo concedidos (R4V, 2019).

Mais de 5 milhões de venezuelanos vivem no exterior (R4V, 2019), e entender como essa diáspora satisfaz suas necessidades é essencial. Infelizmente, os resultados da revisão sistemática da literatura sobre o marketing de diáspora mostram que os estudos relevantes são principalmente qualitativos e descritivos (apenas $23 \%$ dos artigos selecionados são quantitativos, com algum suporte teórico). Alguns estudos buscam explicar os impactos das diásporas de uma perspectiva econômica, como o aumento das oportunidades de comércio entre países devido à vantagem que os migrantes têm em conhecer as necessidades de ambos os países (Artal-Tur, Ghoneim 
\& Peridy, 2015; Kumar \& Steenkamp, 2013; Tien \& Luan, 2015). Outros estudos se concentram nas oportunidades de turismo, envolvidas em levar os migrantes para visitar sua terra natal (Morgan, Pritchard \& Pride, 2003; Murdy, Alexander \& Bryce, 2018; Weaver, Kwek \& Wang, 2017; Yousaf \& Samreen, 2016).

0 caso venezuelano, foco deste estudo, visa explicar como a distância psicológica criada pelos diferentes contextos sociais, espaciais e temporais (que são especificamente diferenças culturais) entre países de origem e países anfitriões de uma diáspora leva ao consumo de produtos nostálgicos. O termo "Nostalgia” em inglês - que possui a mesma grafia na língua portuguesa - é descrito como "um anseio sentimental ou uma afeição melancólica por um período no passado” (Oxford Dictionary, n.d., tradução nossa).

Esta pesquisa traz três contribuições para a literatura emergente sobre o marketing de diáspora. Primeiramente, traz uma revisão detalhada da literatura sobre o tópico, visando distinguir essa perspectiva de outras disciplinas que também examinam o fenômeno "diáspora". Em segundo lugar, o estudo amplia o uso da construal level theory (CLT) (ou teoria do nível de interpretação) (Liberman, Trope \& Wakslak, 2007) a um novo domínio para ajudar a explicar o comportamento dos consumidores em diáspora em um contexto internacional mais abrangente. 0 enfoque em cinco países anfitriões foi inovador, uma vez que os estudos anteriores se concentraram em apenas um, o que significa que a validade teórica externa passa a ser maior. Finalmente, o estudo usa métricas de marketing boca-a-boca digital, ou e-WOM (word of mouth) para confirmar hipóteses sobre a busca dos consumidores da diáspora por produtos nostálgicos. A seção a seguir apresenta uma revisão da literatura realizada para resumir os temas mais comumente estudados no marketing de diáspora.

\section{REVISÃO DA LITERATURA}

Esta revisão visa analisar a literatura sobre o marketing de diáspora, evitando os escritos que dizem respeito a diáspora em geral. Foi realizada uma busca sistemática e focada nesse domínio específico, identificando artigos relevantes nas principais bases de dados e motores de busca, como WoS, EBSCOhost, Science Direct, Emerald, JSTOR e SpringerLink. Foram selecionados apenas artigos publicados nas áreas de comunicação, hotelaria, lazer, esportes, turismo, economia, gestão e negócios. Após a leitura e confirmação que os artigos se encaixam no domínio do marketing de diáspora, foram obtidos 35 artigos na revisão final (Quadro 1). 0 processo contribuiu para a identificação dos principais tópicos de pesquisa relacionados ao marketing de diáspora e permitiu observar a evolução dessa área do marketing, as teorias relevantes, as perspectivas conceituais e as metodologias utilizadas, bem como confirmou a lacuna na literatura que o presente artigo busca preencher.

O conceito de marketing de diáspora é recente e emergente: o interesse acadêmico em marketing de diáspora cresceu lentamente até quatro anos atrás. Dos artigos estudados, $71 \%$ foram publicados após este período, $54 \%$ deles são qualitativos, $43 \%$ são quantitativos e $3 \%$ utilizam métodos mistos. Além disso, $56 \%$ apresentam um suporte teórico: $20 \%$ se apoiam na teoria da aculturação, $11 \%$ em teorias econômicas, $11 \%$ em teorias culturais ou de país, $6 \%$ em teorias psicológicas e $6 \%$ em teorias sociológicas. Os outros $44 \%$ são estudos empíricos e descritivos sem qualquer suporte teórico.

Uma das abordagens teóricas utilizadas foi a teoria da aculturação (TA), que se relaciona com o processo de aculturação do consumidor (Penaloza, 1994). Entre os autores que adotaram essa abordagem estão Brown (1980), que sugere um processo de aculturação na diáspora em quatro etapas; Kumar e Steenkamp (2013), que segmentaram os consumidores em diáspora para ajudar as empresas de mercados emergentes a construir marcas 
internacionais; e Demangeot, Broderick e Craig (2015), que explicaram o processo de adaptação multicultural em mercados localizados geograficamente. Com base no nível de aculturação, autores como Kim e Chen (2016) explicaram a resposta de consumidores em diáspora a estratégias de produto localizadas ou não etnicizadas e Dey, Balmer, Pandit, Saren e Binsardi (2017) explicaram o duplo processo de aculturação da diáspora (adaptação e integração). Ainda, Dey et al. (2019) investigou como o consumo de produtos étnicos afeta a aculturação de consumidores em diáspora e, finalmente, Quinn e Devasagayam (2005) adaptaram e validaram a escala de etnia Suinn-Lew da psicologia social para medir a aculturação de comunidades em diáspora.

\section{Quadro 1. Pesquisas representativas do marketing de diáspora, organizadas por ano}

\begin{tabular}{|c|c|c|c|}
\hline Autores & Método & Perspectiva Teórica/Conceitual & País de origem e país anfitrião \\
\hline $\begin{array}{l}\text { Quinn e } \\
\text { Devasagayam } \\
\text { (2005) }\end{array}$ & Quantitativo & $\begin{array}{l}\text { Aculturação e etnicidade } \\
\text { autoidentificada }\end{array}$ & Comunidade indiana em diáspora nos EUA \\
\hline Frank et al. (2012) & Quantitativo & $\begin{array}{l}\text { Estrutura do índice de satisfação do } \\
\text { cliente }\end{array}$ & Comunidade chinesa em diáspora no Japão \\
\hline $\begin{array}{l}\text { Kumar e } \\
\text { Steenkamp (2013) }\end{array}$ & Qualitativo & Teoria da aculturação & Comunidade indiana em diáspora nos EUA \\
\hline Holak (2014) & Qualitativo & $\begin{array}{c}\text { Abordagem da nostalgia e } \\
\text { perspectivas sociológicas, históricas } \\
\text { e interculturais }\end{array}$ & $\begin{array}{c}\text { Comunidade russa em diáspora } \\
\text { em Nova York, EUA }\end{array}$ \\
\hline $\begin{array}{l}\text { Cross e Gilly } \\
(2014)\end{array}$ & Misto & Teoria do capital cultural & $\begin{array}{l}\text { Pessoas filipinas, mexicanas, taiwanesas, } \\
\text { chilenas, australianas, iranianas, bielorrussas, } \\
\text { vietnamitas e sul-africanas em diáspora, } \\
\text { casados(as) com esposa(o) nascida(o) nos EUA. }\end{array}$ \\
\hline $\begin{array}{l}\text { Demangeot et al. } \\
\text { (2015) }\end{array}$ & Qualitativo & Teoria da aculturação & -- \\
\hline $\begin{array}{l}\text { Artal-Tur et al. } \\
(2015)\end{array}$ & Quantitativo & $\begin{array}{l}\text { Abordagem de rede no relacionamento } \\
\text { de migração comercial }\end{array}$ & Comunidade egípcia em diáspora na França \\
\hline $\begin{array}{l}\text { Badinella e Chong } \\
(2015)\end{array}$ & Qualitativo & $\begin{array}{l}\text { Sociologia econômica, inserção } \\
\text { social e relações sociais }\end{array}$ & $\begin{array}{l}\text { Comunidades negras africanas em diáspora em } \\
\text { Londres, Reino Unido }\end{array}$ \\
\hline Brillon (2015) & Qualitativo & Economia política & $\begin{array}{l}\text { Comunidades filipinas em diáspora em todo o } \\
\text { mundo e nas Filipinas }\end{array}$ \\
\hline Tien e Luan (2015) & Quantitativo & Teorias de comércio internacional & Comunidades chinesas em diáspora em Taiwan \\
\hline $\begin{array}{l}\text { Chandrasen } \\
(2016)\end{array}$ & Quantitativo & Teoria da aculturação & Estudantes internacionais no Reino Unido \\
\hline Kim e Chen (2016) & Qualitativo & Teoria da aculturação & Asiáticos em diáspora nos EUA \\
\hline $\begin{array}{l}\text { Yousaf e Samreen } \\
(2016)\end{array}$ & Quantitativo & Perspectiva de marca do país & $\begin{array}{c}\text { Comunidades paquistanesas em diáspora nas } \\
\text { universidades chinesas e malaias. }\end{array}$ \\
\hline Dey et al. (2017) & Qualitativo & Teoria da aculturação & Asiáticos em diáspora no Reino Unido. \\
\hline $\begin{array}{l}\text { Guzmán et al. } \\
(2017)\end{array}$ & Quantitativo & Autoconceitos & $\begin{array}{c}\text { Mexicanos na Cidade do México e mexicanos em } \\
\text { diáspora na região metropolitana de Dallas/Fort } \\
\text { Worth, EUA }\end{array}$ \\
\hline $\begin{array}{l}\text { Papadopoulos et } \\
\text { al. (2017) }\end{array}$ & Quantitativo & $\begin{array}{l}\text { Imagem produto-país e teoria da } \\
\text { animosidade }\end{array}$ & Egípcios em diáspora no Canadá \\
\hline $\begin{array}{l}\text { Weaver et al. } \\
(2017)\end{array}$ & Qualitativo & $\begin{array}{l}\text { reações cognitivas, afetivas e } \\
\text { conativas }\end{array}$ & Turistas de etnia Chinesa na China Continental \\
\hline $\begin{array}{l}\text { Henthorne et al. } \\
(2018)\end{array}$ & Quantitativo & Teoria da identificação social & $\begin{array}{c}\text { Descendentes Africanos na África do Sul, Brasil } \\
\text { e EUA }\end{array}$ \\
\hline Zhao et al. (2018) & Quantitativo & Efeitos culturais & Consumidores Sino-americanos \\
\hline Dey et al. (2019) & Qualitativo & Teoria da aculturação & Consumidores étnicos em Londres, Reino Unido. \\
\hline
\end{tabular}


Os estudos baseados em teorias econômicas, por outro lado, procuraram principalmente explicar como as redes de migrantes ajudam as empresas nacionais (Brillon, 2015; Artal-Tur et al., 2015; Tien \& Luan, 2015). Badinella e Chong (2015) usaram a sociologia econômica, a inserção social e as relações sociais para estudar as práticas estéticas da comunidade negra em diáspora no mercado de arte. Frank, Abulaiti e Enkawa (2012) exploraram as diferenças na satisfação do cliente, intenção de recompra e marketing boca a boca entre consumidores nascidos na China residindo no Japão e consumidores japoneses em seu próprio país. Yousaf e Samreen (2016) estudaram a influência da mídia na reputação de marca no Paquistão. Mais recentemente, Papadopoulos, Banna e Murphy (2017) avaliaram o efeito da afinidade, animosidade e imagens da pátria nas intenções de compra.

Do ponto de vista sociológico, Henthorne, Williams e George (2018) examinaram o comportamento de reclamação dos consumidores africanos em diáspora com base na teoria da identificação social. Holak (2014) estudou a evocação nostálgica por meio da cozinha tradicional russa. Finalmente, artigos empíricos e descritivos foram dedicados ao estudo do turismo de diáspora (Murdy et al., 2018), a penetração internacional de produtos por meio de redes de consumidores em diáspora (Bundas, 2018), comportamento do consumidor em diáspora (Morgan et al., 2003), alimentação do consumidor (Mostafa, 2018) e sua aculturação e atuação no varejo (Bundy, 2017), bem como danos à imagem da comunidade em diáspora causados notícias negativas (Ogunyemi, 2018).

Independentemente da base teórica usada para estudar os comportamentos de indivíduos em diáspora, os fatores culturais parecem ser um elemento-chave. Para ilustrar seus efeitos, Cross e Gilly (2014) descobriram que famílias com casais imigrantes biculturais se engajaram mais rapidamente com a cultura anfitriã do que as famílias monoculturais. Outro estudo baseado nas dimensões culturais de Hofstede mostrou a influência dos papéis culturais de gênero (Zhao, Sun, Devasagayam e Clendenen, 2018). Da mesma forma, Guzmán, Paswan e Fabrize (2017) mostraram que a percepção de uma marca é diferente para latinos que residem em seu país de origem do que para imigrantes, devido às diferenças culturais. Já Weaver et al. (2017) descobriram que chineses em diáspora têm elevado grau de conexão cultural com a China.

Desde que o presente estudo deu por concluída a revisão sistemática da literatura, outros artigos foram publicados. Entretanto, essas novas pesquisas não alteraram as conclusões aqui apresentadas. Esses novos artigos tiveram por foco a influência das redes de diáspora na difusão de produtos (Elo, Minto-Coy, Silva \& Zhang, 2020; Matejowsky, 2020) e como os níveis de aculturação de comunidades em diáspora estão relacionados às motivações para viagens de lazer e experiência no país de origem (Preez e Govender, 2020).

A revisão mostra que a literatura sobre marketing de diáspora se concentra principalmente em explicar os impactos, os elementos de influência e as oportunidades relacionadas aos negócios. Os estudos, portanto, têm dado pouca importância a compreensão sobre a compra de produtos nostálgicos por parte das comunidades em diáspora, o que é uma lacuna na literatura.

Outro tópico importante a ser analisado é o marketing boca a boca ou word of mouth (WOM), que é a forma como os consumidores compartilham informações sobre produtos, serviços, marcas ou empresas. 0 "boca a boca digital" ou e-WOM, refere-se a esse compartilhamento de informações quando feito pela Internet (por meio de “curtidas” em mídias sociais, resenhas, comentários, tweets, postagens em blogs, etc.) (Rosario, Sotgiu, Valck \& Bijmolt, 2016). As evidências da relação positiva entre o e-WOM e as vendas são abundantes (ver Rosario et al., 2016) e, por esse motivo, medir o e-WOM é uma forma válida de estimar o comportamento de compra. O e-WOM inclui comunicação não textual, como "curtir" ou "retuitar”, bem como publicação de comentários, e pode ser definido como avaliação positiva ou negativa de um cliente potencial ou atual de um anúncio, marca ou empresa. Além disso, um usuário do Instagram, por exemplo, ao invés de escrever um comentário ou compartilhar uma 
postagem, utiliza clicar no botão “curtir” como uma maneira rápida de mostrar sua aprovação, pois, neste caso, os principais métodos de interação e comunicação do Instagram são a postagem de imagens e as curtidas. A literatura sobre comunicação na internet considera curtir e comentar uma postagem como e-WOM, já que essas ações do usuário representam uma expressão de sua opinião pública (Vries, Gensler \& Leeflang, 2012). Especificamente, Rosario et al. (2016) conduziram uma meta-análise e descobriram que o número de curtidas como e-WOM afeta mais as vendas do que qualquer outra métrica de qualificação, seja positiva ou negativa.

\section{REFERENCIAL TEÓRICO E DESENVOLVIMENTO DAS HIPÓTESES}

Diferentes referenciais teóricos foram usados para explicar o marketing de diáspora e eles focaram principalmente na teoria da aculturação (TA) e teorias das áreas de economia, psicologia e sociologia. Esses estudos (Tabela 1), no entanto, foram realizados principalmente em contextos com barreiras linguísticas significativas e uma grande distância cultural entre os países de origem e anfitriões (Chandrasen, 2016; Dey et al., 2017, 2019; Kim \& Chen, 2016). No caso venezuelano não existe barreira linguística, visto que o espanhol é a língua oficial em todos os países estudados. Tampouco há, nesse caso, conflitos militares ou religiosos - condições que costumam gerar animosidade à marca (Papadopoulos et al., 2017). A TA é usada para descrever o processo de adaptação e assimilação da comunidade em diáspora à cultura do país anfitrião (Brown, 1980). A aquisição de produtos nostálgicos indica o fenômeno oposto: a cultura de origem da comunidade em diáspora está sendo afirmada, sinalizando a falta de um processo de aculturação. De-Juan-Vigaray, Garau-Vadell e Sesé (2021) encontraram uma relação entre tempo de residência e aculturação e, posteriormente, aculturação de compras, que se refere ao nível de apego a negócios associados à origem étnica de alguém. Nesse caso, quanto menor o tempo de residência, menos aculturada é a comunidade venezuelana em diáspora, ou seja, há menos aculturação de compras no país anfitrião e manutenção de um apego ao país de origem. Consequentemente, a TA descreve apenas o processo de adaptação da comunidade em diáspora e não possui os mecanismos para explicar uma preferência por produtos nostálgicos, diferentemente da teoria do nível de interpretação (CLT) (Heinberg, Katsikeas, Ozkaya \& Taube, 2019).

Tabela 1. Pesquisa sobre marketing de diáspora usando teorias de aculturação

\begin{tabular}{l|c|c|c}
\hline $\begin{array}{l}\text { País de origem e país } \\
\text { anfitrião }\end{array}$ & Idioma & $\begin{array}{c}\text { Distância Cultural } \\
\text { (Kogut \& Singh, 1988) }\end{array}$ & Autores \\
\hline EUA/Índia & Inglês/Hindi & 75,4 & Quinn e Devasagayam (2005) \\
\hline Japão/China & Japonês/Mandarim & 79,8 & Frank et al. (2012) \\
\hline Reino Unido/Nigéria & Inglês/Hauçá & 87,2 & Badinella e Chong (2015) \\
\hline França/Egito & Francês/Árabe Moderno Padrão & 85,0 & Badinella e Chong (2015) \\
\hline EUA/China & Inglês/Mandarim & 112,1 & Kim e Chen (2016) \\
\hline EUA/Filipinas & Inglês/Tagalo e Inglês & 84,2 & Kim e Chen (2016) \\
\hline EUA/México & Inglês/Espanhol & 87,1 & Papadopoulos et al. (2017) \\
\hline Canadá/Egito & Inglês e Francês/ Árabe Moderno Padrão & 100,0 & Dey et al. (2019) \\
\hline Reino Unido/China & Inglês/Mandarim & 100,7 & \\
\hline
\end{tabular}

Nota: 0 cáuculo da Distância Cultural foi feito usando os indicadores de Hofstede (2019) 
Por esse motivo, o presente estudo usa a CLT como sua estrutura (Liberman et al., 2007), o que ajuda a explicar como as pessoas pensam em eventos “distantes” e porque preferem marcas e produtos nostálgicos que estão associados a eventos socialmente, espacialmente, e temporalmente distantes (Heinberg et al., 2019).

A CLT diz respeito a interpretação dos eventos, sendo que eventos “próximos" são representados por recursos concretos, pouco estruturados, que demandam baixo nível de cognição, de característica casual e ricos detalhes. Em contraste, os eventos distantes são representados por uma abstração que demanda alto nível de cognição, de simbolizações esquemáticas e descontextualizadas, omitindo características casuais e secundárias (Trope, Liberman \& Wakslak, 2007). Descobriu-se que existe uma relação entre distância psicológica e abstração, especificamente, diferença temporal na abstração, o que evidencia a relação entre a interpretação e as dimensões da distância espacial, distância social e a probabilidade de que um evento ocorra (Trope et al., 2007). Especificamente, a semelhança interpessoal é uma forma de distância social: estudos anteriores mostram que pessoas semelhantes são percebidas como socialmente mais próximas umas das outras do que de pessoas diferentes, que está associado à distância social (Liviatan, Trope \& Liberman, 2008).

As comunidades venezuelanas em diáspora estão social, espacial e temporalmente distantes de sua terra natal. A ausência de parentes e amigos acarreta a distância social, o fato de estar longe de sua terra natal indica distância espacial, e o fato de o tempo ter passado desde a infância leva à distância temporal. Por sua vez, a distância pode evocar um anseio por marcas, produtos, serviços e formas de entretenimento oriundos da terra natal.

A CLT afirma que a distância psicológica muda as representações mentais das pessoas sobre os eventos (Liviatan et al., 2008). As diferenças nas dimensões culturais são uma forma de distância social. Quanto maior a similaridade entre os indivíduos, mais próximos socialmente eles parecem. 0 oposto ocorre quando as pessoas de um grupo social sentem que não podem se relacionar com outro grupo; nesse caso, uma diáspora remete a uma maior distância psicológica das pessoas tanto em sua terra natal quanto em seu país anfitrião (Liviatan et al., 2008).

Hofstede (2019) define cultura "como a programação mental coletiva da mente humana que distingue um grupo de pessoas de outro" (p. 6, tradução nossa), o que significa que as diferenças culturais entre a pátria de origem de uma comunidade em diáspora e seu país anfitrião devem criar distância social, conforme indicado pela CLT. As três distâncias psicológicas: sociais, espaciais e temporais estão associadas à decisão de compra no caso de produtos nostálgicos (Heinberg et al., 2019). 0 apego emocional à marca refere-se à conexão afetiva que os consumidores formam com elas, e isso corresponde ao aspecto social da CLT (Heinberg et al., 2019). Como resultado, a distância social está associada a uma preferência por consumir produtos nostálgicos (Heinberg et al., 2019).

As diferenças de dimensão cultural entre o país de origem e o país anfitrião também criam um distanciamento social das comunidades em diáspora que levam a uma preferência pelo consumo de produtos nostálgicos. A distância social aparece quando o país anfitrião possui um nível mais alto de individualismo do que a terra natal, porque nas sociedades coletivistas os indivíduos pertencem a grupos internos fortemente unidos que cuidam deles em troca de lealdade, enquanto que nas sociedades individualistas eles devem cuidar de si próprios (Hofstede, 2019). Isso pode afetar as pessoas em diáspora devido a maior distância social, o que, por sua vez, leva a uma preferência por produtos nostálgicos. Além disso, há evidências de que países coletivistas (como a Venezuela) preferem produtos hedônicos (Talay, Akdeniz, Obal \& Townsend, 2019) e marcas locais (Krautz \& Hoffmann, 2017). Consequentemente, elabora-se a seguinte hipótese: 
H1: Em países anfitriões onde o individualismo é mais elevado do que no país de origem, as compras de produtos nostálgicos realizadas por consumidores em diáspora são maiores do que em países anfitriões onde o individualismo é similar ao encontrado no país de origem.

Da mesma forma, quando há uma diferença entre o país de origem das comunidades em diáspora e o país anfitrião em termos da dimensão cultural da masculinidade, pode haver uma sensação de aumento da distância social. Altos níveis de masculinidade indicam que uma sociedade é movida pela competição, realização e sucesso, enquanto altos níveis de feminilidade significam que o valor dominante na sociedade é cuidar do próximo, que a qualidade de vida é um importante sinal de sucesso e que destacar-se na multidão não é admirável (Hofstede, 2019). Isso sugere que comunidades em diáspora oriundas de um país com alta masculinidade vivendo em um país anfitrião onde há uma maior feminilidade podem tender a consumir produtos de sua terra natal como um sinal de sucesso. Para pessoas de um país com alta masculinidade como a Venezuela, o sucesso e o reconhecimento são uma parte inerente das normas sociais (Hofstede, 2019). Para os grupos masculinos, comprar produtos caros e da última moda em diferentes lojas especializadas é uma forma de mostrar sucesso e status (Kumar \& Pansari, 2016). Ainda, a evocação nostálgica por meio da culinária tradicional da terra natal pode estabelecer uma conexão social (Holak, 2014), o que significa que comprar produtos nostálgicos poderá sinalizar sucesso, já que seriam produtos importados e caros, e seu consumo representa um indício de sucesso (Talay, Townsend e \& Yeniyurt, 2015). Portanto, a seguinte hipótese é postulada:

H2: Em países anfitriões com menor masculinidade em comparação com a terra natal das comunidades em diáspora, as compras de produtos nostálgicos por parte dessa comunidade são maiores do que quando os países anfitriões apresentam uma masculinidade igual a do país de origem.

Imigrantes recém-chegados ainda precisam encontrar maneiras de gerar renda suficiente para atender às suas necessidades básicas, como alimentação, moradia, saúde e educação. Apesar de sua herança espanhola comum, os países latino-americanos apresentam diferentes níveis de desenvolvimento econômico (Vassolo, Castro \& Gomez-Mejia, 2011).

O desenvolvimento econômico de um país influencia todos os seus agentes econômicos, sendo que um baixo desenvolvimento indica que as empresas terão menos clientes, menos canais de distribuição, menos infraestrutura, menos oportunidades de negócios e maiores riscos que influenciam as decisões tomadas pelos latino-americanos (Palomino-Tamayo, Timana \& Cerviño, 2020). O desenvolvimento econômico de um país também influencia as decisões do consumidor das marcas e o desempenho delas no mercado (Talay et al., 2015). 0 menor desenvolvimento nos países latino-americanos é caracterizado pela falta de empregos, onde as pessoas recorrem a empregos informais para sobreviver (Vassolo et al., 2011) e há um contexto que gera dificuldades econômicas pessoais, desperta animosidade em relação à compra de produtos estrangeiros (produtos do país anfitrião) e resulta em uma preferência por produtos relacionados ao grupo (Leonidou, Kvasova, Christodoulides \& Tokar, 2019). Consequentmente, essa animosidade cria uma distância social que fortalece o senso de pertencimento entre venezuelanos em diáspora e leva a uma preferência pelo consumo de produtos nostálgicos, como prevê a CLT. Assim, elabora-se a seguinte hipótese:

H3: Em países anfitriões com menor (maior) desenvolvimento econômico do que o país de origem, as compras de produtos nostálgicos por parte da comunidade em diáspora são maiores (menores) do que nos países anfitriões em que o desenvolvimento econômico é maior (menor) do que na terra natal. 
A proximidade geográfica reduz os custos de transporte e comunicação e facilita a interação pessoal, a troca de informações e o comércio internacional (Ghemawat, 2001). A maior distância geográfica entre o país de origem e o país anfitrião aumenta a distância espacial, o que distorce as percepções (Choi \& Yeniyurt, 2015), causando um sentimento de saudade de casa que as comunidades em diáspora tentam amenizar consumindo produtos nostálgicos (Heinberg et al., 2019). Portanto, diásporas em países geograficamente distantes de sua terra natal tendem a buscar o consumo de produtos nostálgicos em maior grau. Consequentemente, apresenta-se a quarta hipótese:

H4: As compras de produtos nostálgicos por parte da comunidade em diáspora são maiores em países anfitriões que ficam mais distantes geograficamente do país de origem do que no caso de comunidades em diáspora que emigraram para países anfitriões que ficam geograficamente mais próximas do país de origem.

\section{METODOLOGIA}

\section{Fonte dos dados e amostra}

Em plataformas de mídia social como Facebook, Twitter e Instagram, os usuários podem seguir outros, comentar sobre suas postagens e rastrear os posts assinalados como "curtir" e comentários que suas próprias postagens recebem. Embora o Facebook e o Twitter incorporem imagens, os usuários também dependem muito de texto, postagens compartilhadas e outros tipos de interações sem imagens. No Instagram, no entanto, as imagens dominam e seus usuários contam com "curtir" como o principal meio de interação e comunicação (Schmeichel, Kerr \& Linder, 2020).

O foco exclusivo do Instagram em imagens o diferencia de outras plataformas e é a razão pela qual o Instagram foi escolhido como a fonte de dados para esta pesquisa. 0 uso de fotografias e imagens faz com que um dos assuntos mais recorrentes seja a relação entre o Instagram e a nostalgia. Vários autores atribuem essa relação entre Instagram e nostalgia à estética dos filtros que ele utiliza, que podem reproduzir facilmente uma combinação de texturas de filmes, formatos de enquadramento, tons, pátinas e efeitos vintage, incluindo cores quentes e o formato quadrado das câmeras Kodak e Polaroid, matização de cores e formatos de borda que lembram a tecnologia analógica (Wagner, 2018). Em resumo, o Instagram é a plataforma mais adequada para estudar a nostalgia.

Tão importante quanto e em contraste com o Facebook, é comum que os usuários do Instagram sigam, vejam, curtam e comentem fotos de pessoas que não conhecem pessoalmente. Mas o número de estranhos seguidos e a maior frequência de postagem estão associados à depressão (Reece \& Danforth, 2017) - e devido aos processos de aculturação que as comunidades em diáspora vivenciam, a depressão é de fato comum entre eles (Brown, 1980). A associação do Instagram com a depressão o torna uma fonte de dados apropriada para este estudo com foco na nostalgia.

Muitas pessoas na diáspora venezuelana no Instagram frequentemente procuram informações sobre o status de imigração e veem publicidade orientada para a Venezuela (veja a Tabela 2). Os perfis do Instagram mostrados na Tabela 2 foram selecionados porque possuem o maior número de seguidores em cada país anfitrião e efetuam postagens publicitárias que podem ser analisadas. 
Tabela 2. Comunidades online de venezuelanos em diáspora, por país

\begin{tabular}{l|l|c|l}
\hline PAÍS & REDE SOCIAL INSTAGRAM & SEGUIDORES & LINK \\
\hline COLÔMBIA & Tu Pana en Colombia & $72,2 \mathrm{mil}$ & $\underline{\text { https://www.instagram.com/tupanaencolombia/ }}$ \\
\hline PERU & Peruzuela & $150 \mathrm{mil}$ & $\underline{\text { https://www.instagram.com/peruzuela/?hl=es-la }}$ \\
\hline CHILE & Venezolanos en Chile & $411 \mathrm{mil}$ & $\underline{\text { https://www.instagram.com/venezolanosenchile/ }}$ \\
\hline EQUADOR & Venezolanos En Ecuador & $21,8 \mathrm{mil}$ & https://www.instagram.com/venezolanosenecuadoroficial/?hl=es-la \\
\hline PANAMÁ & Panazolanos & $39,7 \mathrm{mil}$ & https://www.instagram.com/panazolanos/?hl=es-la \\
\hline
\end{tabular}

\section{Medidas}

Conforme demonstrado na revisão da literatura, as curtidas do marketing boca a boca digital (e-WOM) são uma métrica poderosa que afeta as vendas (Rosario et al., 2016). Assim, este estudo considera o número de curtidas em postagens de publicidade como uma medida de e-WOM entre as comunidades venezuelanas online no Instagram que estão em diáspora na Colômbia, Peru, Chile, Equador e Panamá.

Os índices de Hofstede (Hofstede, 2019) foram usados na medição das dimensões culturais. Para classificar cada país anfitrião aplicando as dimensões de masculinidade/feminilidade e individualismo, foi utilizada a distância cultural (Kogut \& Singh, 1988), nesse caso, apenas para fins de classificação, existindo uma dimensão por agrupamento. A distância cultural entre o país anfitrião e a Venezuela mostra se o país é maior ou menor que ela em dimensão cultural. 0 modelo cultural de Hofstede foi usado nesta pesquisa pela sua adequação ao estudo na escala de país, ao invés do modelo de Schwartz que é apropriado para aplicação em nível individual - o que não é o caso neste estudo (para uma discussão mais aprofundada, ver Fischer, Vauclair, Fontaine \& Schwartz, 2010).

Para mensurar a distância do desenvolvimento econômico entre país de origem (Venezuela) e os países anfitriões, foi adotada a diferença percentual no PIB per capita de 2018 (Palomino-Tamayo et al., 2020), adotando como fonte de informação o banco central de cada país.

Já a distância geográfica foi mensurada pela distância entre as capitais da Venezuela e dos países anfitriões, a partir das coordenadas geográficas registradas na base de dados GeoDist, CEPII (2019).

A partir de uma busca realizada na plataforma Instagram entre os meses de maio e outubro de 2019, obteve-se uma amostra total de 44 postagens publicitárias feitas em grupos de venezuelanos em diáspora na Colômbia, 40 no Peru, 40 no Chile, 84 no Equador e 50 no Panamá. A amostra final somou 258 anúncios, que receberam ao todo 30.785 curtidas (métrica de e-WOMs utilizada), ou seja, uma média de 119 e-WOMs por anúncio. As postagens de publicidade foram submetidas a revisão por dois pesquisadores que as classificaram em dez categorias diferentes. Os pesquisadores são professores de marketing com conhecimento em publicidade que não se envolveram de outra forma no estudo e, para evitar qualquer viés, não receberam informações anteriores sobre seu título, objetivos ou hipóteses. Os anúncios foram facilmente classificados devido à natureza gráfica das publicações do Instagram e à franqueza do texto que as acompanhava. Os dois pesquisadores e os autores do estudo definiram os nomes das categorias e consolidaram todos os serviços (manifestados de forma bastante diversa nas postagens) em apenas uma categoria, "serviços relacionados à Venezuela". Um dos pesquisadores dividiu a categoria "procura-se ajudante" em duas subcategorias: "procura-se ajudante especializado" e "procura-se ajudante geral". A principal diferença na classificação realizada por cada pesquisador se deu nos nomes atribuídos às categorias, o que foi facilmente ajustado dada a grande semelhança observada entre elas. 
Uma segunda revisão foi conduzida para categorizar os anúncios como "nostálgicos" ou "econômicos". Quando os autores discordaram da classificação, submeteram os anúncios à uma nova revisão. Os produtos e serviços nostálgicos relacionados ao país de origem (o foco principal do estudo), incluíram comida venezuelana (arepas, tamales, chocolates, pão de presunto, etc.), entretenimento venezuelano (festas ou concertos com música e artistas venezuelanos), serviços relacionados a Venezuela (serviços de envio de presentes e remédios aos parentes na Venezuela, importação de alimentos e passagens aéreas ou de ônibus do país anfitrião para a Venezuela) e transferência de dinheiro (devido às restrições do governo venezuelano, esses serviços somente permitiam envios em moeda venezuelana). Os produtos econômicos incluíam anúncios de procura de ajudante (anúncios colocados por agências de empregos; anúncios de feiras de empregos voltados para os venezuelanos; e anúncios de procura de ajudante geral para trabalho manual, vendas e cargos administrativos que não exigiam nenhum treinamento prévio), anúncios de procura de ajudante especializado (anúncios que procuram técnicos e profissionais, como eletricistas, barbeiros, padeiros e engenheiros com algum grau de especialização e experiência), anúncios de oportunidades educacionais (cursos técnicos ou programas para obter certificações do país anfitrião), anúncios de produtos básicos de consumo (computadores, telefones celulares, medicamentos de venda livre) e anúncios de serviços financeiros (hipotecas e empréstimos para a compra de veículos).

\section{RESULTADOS}

Três das dez categorias de publicidade identificadas receberam a maioria das curtidas: entretenimento venezuelano, comida venezuelana e anúncios do tipo "procura-se ajudante", sendo que houve alguma variação dependendo do país anfitrião. A Tabela 3 exibe as estatísticas descritivas do e-WOM para cada categoria de anúncio e resume o comportamento do e-WOM da comunidade venezuelana em diáspora. Anúncios de entretenimento venezuelano geraram mais e-WOM no Peru (média $=255$ e DP $=252$ ) e no Equador (média $=124$ e DP $=159$ ). Também foram importantes no Panamá (média = 13 e DP =7), Colômbia (média = 104 e DP =66) e Chile (média = 309 e DP=141). Os anúncios em busca de ajudantes foram os mais curtidos na Colômbia (média $=204$ e DP =78), o segundo mais curtido no Chile (média = 433 e DP = 162), e não tão relevante no Equador (média $=57$ e DP = 35) e no Panamá (média $=6$ e DP $=7$ ). Outra categoria que gerou alto e-WOM em todos os países foi a comida venezuelana, especialmente na Colômbia (média = 149 e DP = 39), Peru (média = 118 e DP=68), Equador (média = 92 e DP=73), e Panamá (média $=12$ e DP = 10). Alguns casos excepcionais foram observados: no Panamá, os anúncios de oportunidades educacionais geraram os maiores e-WOM (média $=15$ e DP $=2$ ) naquele país, enquanto no Chile os anúncios de serviços financeiros foram os que mais geraram e-WOM (média $=804$ e DP $=478$ ).

Uma análise de variância (ANOVA) e o Teste t de Welch foram conduzidos para testar as hipóteses, onde a variável dependente para cada grupo de países anfitriões foi o e-WOM dos anúncios. Em primeiro lugar, os países anfitriões foram classificados, usando percentual de distância cultural (DC), como apresentando maior individualismo (Peru DC $=+33 \%$ e Chile DC $=+92 \%$ ), ou individualismo em nível semelhante ao da Venezuela (Colômbia $\mathrm{DC}=+8 \%$, Equador DC $=-33 \%$ e Panamá $\mathrm{DC}=-8 \%$ ). Os resultados indicam diferenças entre os grupos que são consistentes com a H1: países com maior individualismo que a Venezuela (média $=205$ e DP $=38,8$ ), têm e-WOM maior do que países com igual individualismo (média $=74$ e DP $=9,7$ ) (Figura $1-A$ ). A diferença é significativa e positiva (Mdif = 131, DPdif = 39,9, GL de Welch = 39,7, t =-3,27, p < 0,01) e confirma a hipótese H1. Como verificação de robustez, a estimativa foi executada sem os dados do Equador. Os resultados indicaram 
que os outros países ainda tinham aproximadamente o mesmo nível de individualismo (média $=43$ e DP $=57$ ). A diferença permaneceu significativa e positiva (Mdif = 162, GL de Welch =38,1, t=-4,099, $p<0,0001$ ); portanto, os resultados permaneceram válidos.

Tabela 3. Estatísticas descritivas do e-WOM por país e categoria de publicidade

\begin{tabular}{|c|c|c|c|c|}
\hline & MÉDIA & DESVIO PADRÃO & MIN & MAX \\
\hline \multicolumn{5}{|l|}{ COLÔMBIA } \\
\hline Procura-se ajudante & 204 & 78 & 110 & 315 \\
\hline Comida venezuelana & 148 & 59 & 65 & 226 \\
\hline Entretenimento venezuelano & 104 & 66 & 51 & 178 \\
\hline Consultoria de trabalho & 44 & 14 & 28 & 70 \\
\hline Serviços relacionados à Venezuela & 36 & 11 & 20 & 43 \\
\hline Transferência de dinheiro & 29 & 12 & 13 & 49 \\
\hline \multicolumn{5}{|l|}{ PERU } \\
\hline Entretenimento venezuelano & 255 & 252 & 24 & 602 \\
\hline Oportunidades educacionais & 142 & 133 & 32 & 517 \\
\hline Doação de telefone celular & 121 & 93 & 39 & 362 \\
\hline Comida venezuelana & 117 & 68 & 41 & 173 \\
\hline Serviços relacionados à Venezuela & 91 & 49 & 18 & 146 \\
\hline \multicolumn{5}{|l|}{ CHILE } \\
\hline Serviços financeiros & 804 & 478 & 294 & 1243 \\
\hline Procura-se ajudante & 433 & 162 & 194 & 643 \\
\hline Entretenimento venezuelano & 309 & 141 & 134 & 593 \\
\hline Serviços relacionados à Venezuela & 187 & 81 & 29 & 274 \\
\hline Serviço especializado & 145 & 57 & 76 & 238 \\
\hline \multicolumn{5}{|l|}{ ECUADOR } \\
\hline Entretenimento venezuelano & 124 & 159 & 23 & 855 \\
\hline Serviços relacionados à Venezuela & 94 & 72 & 15 & 258 \\
\hline Comida venezuelana & 92 & 73 & 30 & 236 \\
\hline Oportunidades educacionais & 58 & 52 & 4 & 195 \\
\hline Procura-se ajudante & 57 & 35 & 2 & 114 \\
\hline Serviço especializado & 46 & 15 & 30 & 66 \\
\hline Transferência de dinheiro & 30 & 2 & 32 & 119 \\
\hline \multicolumn{5}{|l|}{ PANAMA } \\
\hline Oportunidades educacionais & 15 & 2 & 13 & 17 \\
\hline Entretenimento venezuelano & 13 & 7 & 7 & 20 \\
\hline Comida venezuelana & 12 & 10 & 2 & 22 \\
\hline Procura-se ajudante & 6 & 7 & 1 & 24 \\
\hline Produtos de consumo básico & 5 & 3 & 2 & 12 \\
\hline Serviços relacionados à Venezuela & 4 & 3 & 1 & 12 \\
\hline
\end{tabular}


Posteriormente, os países anfitriões foram classificados, usando percentual de DC, como apresentando um menor grau de masculinidade (Peru $=-42 \%$, Chile $=-62 \%$ e Panamá $=-40 \%$ ), ou igual masculinidade em relação a Venezuela (Colômbia DC $=-12 \%$ e Equador DC $=-14 \%$ ). Também aqui há diferenças nos resultados (Figura 1 - B) entre países com masculinidade menor que a Venezuela (média = 118 e DP =16,2), que possuem e-WOM maior, e países com masculinidade igual (média $=67$ e DP $=11,4$ ). Da mesma forma, a diferença é significativa e positiva (Mdif = 51, DPdif = 19,1, GL de Welch = 133,2, $t=2,59, \mathrm{p}<0,01)$, confirmando a H2.

Para testar a H3, os países anfitriões foram classificados como países com uma maior distância de desenvolvimento econômico em relação a Venezuela (Chile e Panamá) ou uma menor distância de desenvolvimento econômico em relação a Venezuela (Peru, Colômbia e Equador). Nesse caso, foram poucas as diferenças nos resultados (Figura 1 - C). Países anfitriões com maior distância de desenvolvimento econômico (média = 131 e DP $=45,4$ ), apresentaram valores de e-WOM semelhantes aos de países com menor distância de desenvolvimento econômico (média $=100$ e DP =10,6). Neste caso, a diferença não é significativa (Mdif = 31, DPdif = 46,6, $\mathrm{GL}$ de Welch $=-34,6, t=-0,65, p=0,74)$ e, portanto, a H3 não foi confirmada.

Já no caso da $\mathrm{H}_{4}$, os países anfitriões foram classificados por sua distância geográfica em relação ao país de origem. Colômbia e Panamá são mais próximos da Venezuela, enquanto Equador, Peru e Chile são mais distantes geograficamente. Os países anfitriões a uma distância geográfica maior (média = 144 e DP =18,9), tiveram valores de e-WOM mais altos (ver Figura 1 - D) do que os países anfitriões que estavam mais próximos (média $=43$ e DP $=7$ ). A diferença foi significativa e positiva (Mdif $=101$, DPdif $=20,5, \mathrm{GL}$ de Welch $=118,7, t=4,92, p<$ $0,001)$, confirmando a $\mathrm{H}_{4}$.

Finalmente, o efeito médio do tratamento (ATE) da população foi estimado (Tabela 4) com base em uma comparação direta entre comunidades de diáspora separadas em grupo de tratamento e grupo de controle, que receberam diferentes níveis de tratamento pareado por meio de observação - uma comparação que pode ser interpretada como causal (Imbens \& Rubin, 2015). Primeiro, o efeito do tratamento para grupos em diáspora em países com alto individualismo foi estimado usando a métrica e-WOM. Masculinidade, distância de desenvolvimento econômico e distância geográfica foram usados como covariáveis. O resultado mostra um efeito de tratamento significativo e positivo para países anfitriões com alto individualismo ( $A T E=70, z=2,62, p=0$,009). Então, quando o grupo de países anfitriões com níveis mais baixos de masculinidade foi colocado no grupo de tratamento e os países anfitriões com masculinidade igual a observada na Venezuela foram mantidos como o grupo de controle, com individualismo, distância de desenvolvimento econômico e distância geográfica como covariáveis, houve um efeito positivo e significante para países com baixos níveis de masculinidade (ATE $=48, z$ $=2,58, p=0,010)$. Da mesma forma, quando a distância geográfica foi a variável tratada e masculinidade e distância de desenvolvimento econômico foram covariáveis, um efeito significativo e positivo foi encontrado para 0 grupo em diáspora em um país geograficamente mais distante (ATE $=114, z=4,04, p<0,001$ ). Esses resultados estão em harmonia com as hipóteses $\mathrm{H}_{1}, \mathrm{H}_{2}$ e H4.

A metodologia ATE pode ser usada para interpretar os efeitos causais (Imbens \& Rubin, 2015). Para comunidades em diáspora no grupo de países anfitriões com menor desenvolvimento econômico, a estimativa do efeito do tratamento com individualismo e distância geográfica como covariáveis não exibe efeito significativo ( $A T E=-0,27, z=-0,01, p=0,993)$. Portanto, uma inferência causal para a H3 não pode ser feita. Conforme mencionado, esses efeitos são estimados para anúncios de produtos nostálgicos. Para grupos de diáspora em países anfitriões com uma maior distância de desenvolvimento econômico (com masculinidade e distância geográfica como covariáveis), foi encontrado um efeito de tratamento significativo e positivo ( $A T E=123, z=3,11, p=0,002$ ). 
Figura 1. Resultados da ANOVA, anúncios e-WOM de produtos nostálgicos de países anfitriões

A. Dimensão cultural do individualismo dos países anfitriões em relação ao país de origem

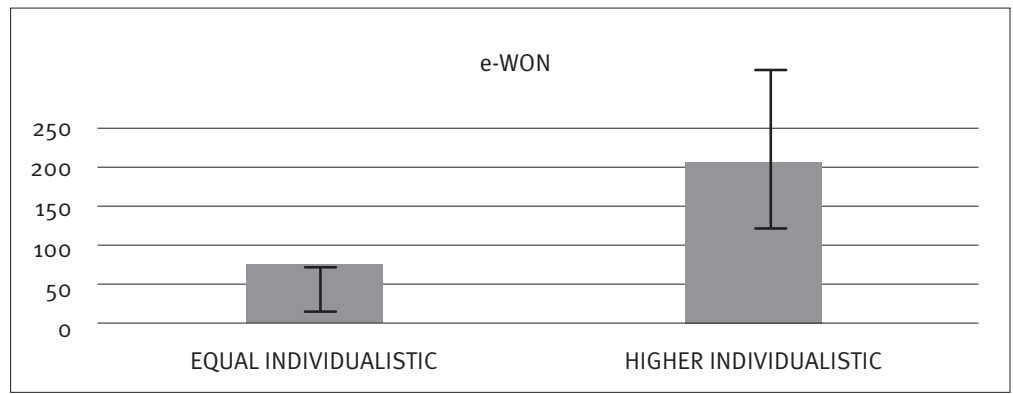

B. Dimensão cultural da masculinidade dos países anfitriões em relação ao país de origem

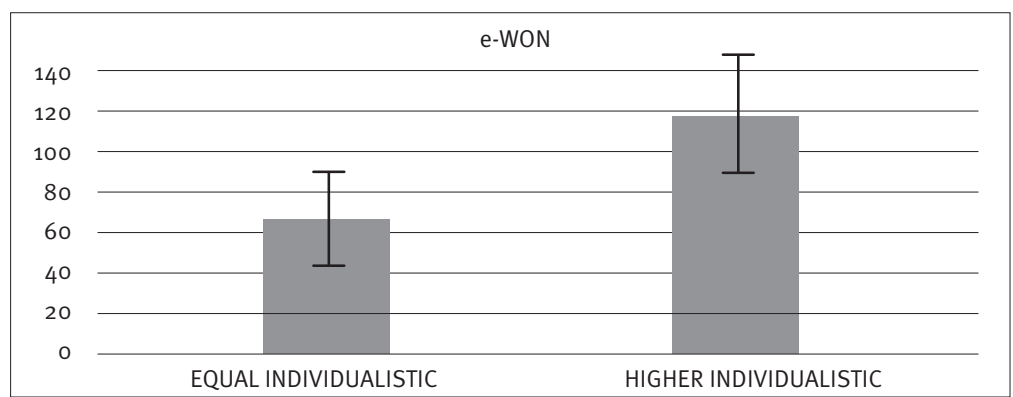

C. Distância de desenvolvimento econômico entre os países anfitriões e o país de origem

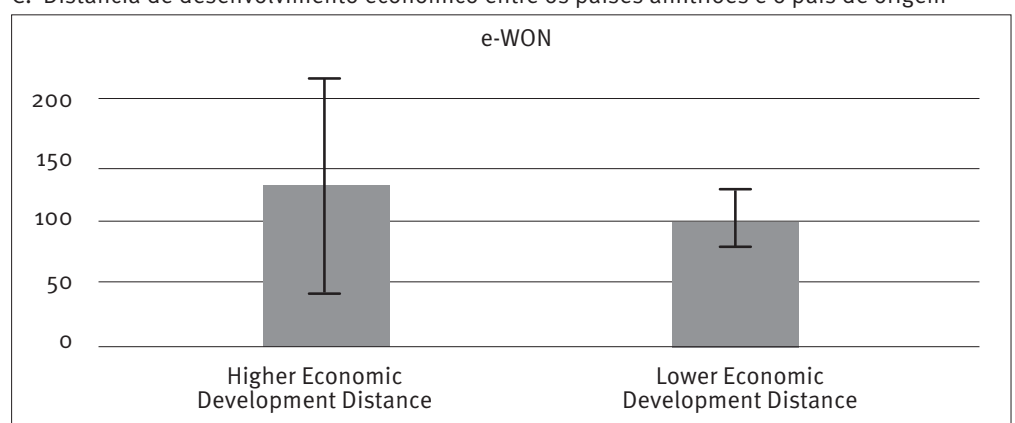

D. Distância física entre os países anfitriões e o país de origem

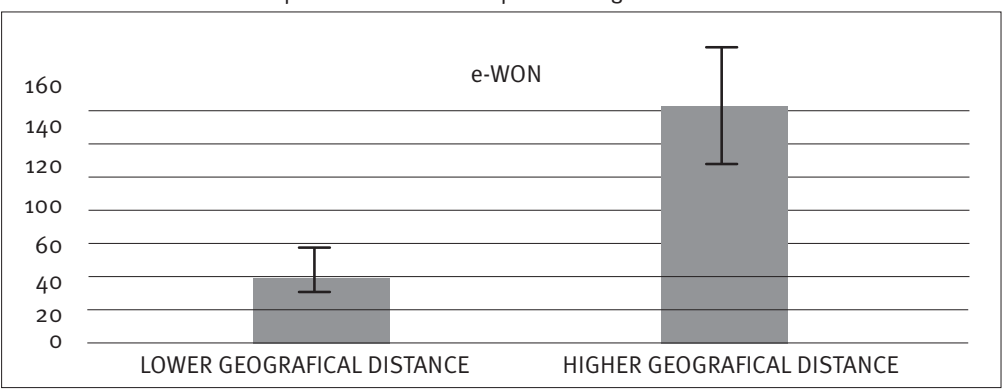

工 Intervalo de confiança de $95 \%$. Barras com média por condição. 
Tabela 4. Resultados: Efeito médio do tratamento (ATE) na população (efeito e-WOM)

\begin{tabular}{l|c|c|c|c|l}
\hline eWOM & Coef. & Erro Padrão & Z & p & Hipóteses \\
\hline Maior individualismo x Igual individualismo & 70 & 27 & 2,62 & $<0,010$ & H1 comprovada \\
\hline Igual masculinidade x Menor masculinidade & -48 & 19 & $-2,58$ & $<0,010$ & H2 comprovada \\
\hline $\begin{array}{l}\text { Maior distância de desenvolvimento econômico x } \\
\text { Menor distância de desenvolviento econômico }\end{array}$ & $-0,27$ & 29 & $-0,01$ & $>0,10$ & H3 não comprovada \\
\hline Maior distância geográfica x Menor distância geográfica & 114 & 28 & 4,02 & $<0,001$ & H4 comprovada \\
\hline
\end{tabular}

Para avaliar a validade do projeto, foram seguidas as recomendações de Gliner, Morgan e Leech (2011). Primeiramente, um banco de dados e todas as informações disponíveis foram utilizado. Não houve nenhum observador, nenhum viés de observador, viés de método comum ou viés de amostra. Em segundo lugar, as variáveis independentes de distância cultural e geográfica permaneceram estáveis ao longo do tempo, ou seja, nenhuma mudança externa as impactou. Terceiro, os resultados robustos de dois métodos de estimativa (ANOVA e Teste t de Welch) confirmaram que o estudo pode ser considerado como um precedente. Quarto, o procedimento de pareamento permite uma interpretação causal em vez da mera observação de uma associação, sem preocupação com a endogênese (Imbens \& Rubin, 2015).

Por fim, a mensuração é adotada em um contexto nomológico semelhante, apoiada por literatura de alta qualidade que oferece um desenho geral com boa validade interna. Finalmente, o fato do estudo ter coberto cinco países ofereceu adequada validade externa, maior que a de pesquisas anteriores sobre o tema.

\section{DISCUSSÃO}

Esta pesquisa comprova que, como previu a construal level theory (CLT) (ou teoria do nível de interpretação), a distância social favorece a preferência dos imigrantes por produtos do país de origem devido à nostalgia. Isso contrasta com os resultados de estudos anteriores, que se referiam apenas a marcas posicionadas como "nostálgicas”, mas não necessariamente associadas a terra natal ou país de origem (Heinberg et al., 2019). Da mesma forma, os resultados mostram que a distância espacial entre o país anfitrião e o país de origem influencia a preferência do consumidor em diáspora por produtos de seu país de origem. De acordo com a revisão da literatura e até onde se sabe, nenhuma pesquisa anterior abordou este tema. Esses resultados são significativos porque abrem oportunidades de mercado nos próximos anos para produtos caseiros com foco nas comunidades em diáspora e para famílias da geração seguinte de imigrantes, aproveitando esse apelo nostálgico resultante da distância social e espacial.

\section{CONCLUSÕES}

Os resultados oferecem implicações interessantes para a teoria sobre o comportamento do consumidor internacional, pois ilustram como a distância psicológica impulsiona o comportamento das comunidades em diáspora em um cenário envolvendo vários países. Os resultados mostram como as diferenças culturais (as dimensões individualismo/coletivismo e masculinidade/feminilidade de Hofstede) entre a terra natal e o país anfitrião pro- 
duzem distância social para as pessoas em diáspora, as incentivando a adquirir produtos nostálgicos. Usando a teoria do nível de interpretação (CLT), essas dimensões culturais explicam a influência da cultura no desenvolvimento da distância psicológica. A literatura anterior, em contraste, focava principalmente em como as diferenças de linguagem criavam estresse entre indivíduos em diáspora. Esses resultados podem ser estendidos para incluir casos de migração intrarregional em que não há diferença de idioma. 0 entretenimento e a comida venezuelana são considerados laços sociais que conectam as pessoas à sua terra natal por meio da nostalgia.

Os resultados também são consistentes com a ideia baseada na CLT de que a distância geográfica cria distância espacial. Se o país anfitrião estiver geograficamente longe da terra natal, a distância espacial é maior e leva a um maior consumo de produtos nostálgicos por parte da comunidade em diáspora.

Ao contrário do que assumido na hipótese $\mathrm{H}_{3}$, os resultados mostraram que não houve preferência por produtos nostálgicos entre consumidores em diáspora em países com diferentes níveis de desenvolvimento econômico. Este resultado pode ter se dado por fatores psicológicos dos imigrantes, que não estão necessariamente relacionados ao status econômico do país anfitrião.

A aquisição de produtos e serviços nostálgicos pode criar demandas que as indústrias de alimentos embalados do país anfitrião de grupos em diáspora podem explorar, aproveitando esse crescente segmento de produtos e serviços que talvez conquiste até consumidores locais, nativos do país anfitrião.

Esta pesquisa pode orientar as decisões de governos e organizações internacionais para mitigar os efeitos da distância psicológica. De fato, esses órgãos poderiam considerar promover a comercialização de produtos naturais (neste caso, venezuelanos) para auxílio das comunidades em diásporas, já que a migração é um problema social para o país anfitrião e psicológico para o migrante.

Embora este estudo contribua elucidando o comportamento de consumidores em diáspora em relação ao consumo de produtos nostálgicos, ele tem suas limitações. Uma delas é o contexto online e o uso de curtidas no Instagram como medida. A maioria dos imigrantes venezuelanos eram jovens, assim como os usuários do Instagram em geral, portanto, significa que pessoas de mais idade não foram necessariamente considerados na amostra. Para um panorama ideal, esta pesquisa poderia estender-se para envolvimento das comunidades em diáspora de forma offline.

Em segundo lugar, como afirma Hofstede (2019), usar dimensões culturais em uma análise "não implica que todos em uma determinada sociedade sejam programados da mesma maneira” (p. 6, tradução nossa). Como tal, um exame de como a cultura do país anfitrião influencia a cultura individual é um caminho rico para a pesquisa.

Como argumenta a literatura tradicional, outra limitação do estudo é que a aculturação das comunidades em diáspora é um processo que possui diferentes estágios psicológicos (Brown, 1980). Esses estágios podem influenciar seus padrões de consumo. No entanto, como a amostra venezuelana é uma comunidade migrante relativamente nova, pode-se presumir que a maioria deles são recém-chegados. Estudar a diferença de tempo de acordo com a CLT pode ser proveitoso, iniciando com a distância do tempo psicológico (Liberman et al., 2007).

A presente revisão da literatura contribui para distinguir entre o tópico da diáspora geral e o tópico mais específico do marketing de diáspora. Assim, pode ser considerada como um ponto de partida para os pesquisadores de marketing explorarem novas ideias de futuros trabalhos nesse emergente campo de estudo. 


\section{REFERÊNCIAS}

Artal-Tur, A., Ghoneim, A. F., \& Peridy, N. (2015). Proximity, trade and ethnic networks of migrants: Case study for France and Egypt. International Journal of Manpower, 36(4), 619-648. doi: 10.1108/IJM-02-2014-0062

Badinella, C., \& Chong, D. (2015). Contemporary Afro and two-sidedness: Black diaspora aesthetic practices and the art market. Culture and Organization, 21(2), 97-125. doi: $10.1080 / 14759551.2013 .806507$

Brillon, C.. (2015). From local to global: Philippine broadcast networks and the Filipino diaspora. International Journal of Communication, 9, 19. Retrieved from https://ijoc.org/index. $\mathrm{php} / \mathrm{ijoc} /$ article/view/2652

Brown, H. (1980). The optimal distance model of second language acquisition. TESOL Quarterly, 14(2), 157-164. doi: $10.2307 / 3586310$

Bundas, A. (2018). Diaspora networks and the consumption of nostalgic products among Romanian migrants in Germany. Oradea Journal of Business and Economics, 3(2), 86-99. Retrieved from https://www.econstor.eu/ bitstream/10419/69357/1/733628729.pdf

Bundy, L. (2017). Expatriates go shopping: Food and shopping acculturation. International Journal of Retail \& Distribution Management, 45 (10), 1079-1094. doi: 10.1108/ IJRDM-08-2016-0127

Centre d'Études Prospectives et d'Informations Internationales (2019). Research and expertise in the world economy. Geodist. Retrieved from http://www.cepii.fr/CEPII/en/bdd_modele/ download.asp?id=6

Chandrasen, A. (2016). Sojourner consumer behaviour: The influence of nostalgia, ethnocentrism, cosmopolitanism and place attachment (Doctoral dissertation, Lancaster University, Lancaster-UK). Retrieved from: https://www.proquest.com/ openview/ae23542546af7a77f4edfgfdfe4f8aob/1?pq-origsit $\mathrm{e}=\mathrm{gscholar} \& \mathrm{cbl}=18750 \&$ diss $=y$

Choi, J., \& Yeniyurt, S. (2015). Contingency distance factors and international research and development (R\&D), marketing, and manufacturing alliance formations. International Business Review, 24(6), 1061-1071. doi: 10.1016/j.ibusrev.2015.04.007

Cross, S. N., \& Gilly, M. C. (2014). Cultural competence and cultural compensatory mechanisms in binational households. Journal of Marketing, 78(3), 121-139. doi: 10.1509/jm.11.0310

De-Juan-Vigaray, M. D., Garau-Vadell, J. B., \& Sesé, A. (2021). Acculturation, shopping acculturation, and shopping motives of international residential tourists. Tourism Management, 83, 1-9. 104229. doi: 10.1016/j.tourman.2020.104229

Demangeot, C., Broderick, A. J., \& Craig, C. S. (2015). Multicultural marketplaces: New territory for international marketing and consumer research. International Marketing Review, 32(2), 118-140. doi: 10.1108/IMR-01-2015-0017
Dey, B., Alwi, S., Yamoah, F., Agyapong, S., Kizgin, H., \& Sarma, M. (2019). Towards a framework for understanding ethnic consumers' acculturation strategies in a multicultural environment: A food consumption perspective. International Marketing Review. 36(5), 771-804. doi: 10.1108/IMR-03-2018-0103

Dey, B. L., Balmer, J. M., Pandit, A., Saren, M., \& Binsardi, B. (2017). A quadripartite approach to analysing young British South Asian adults' dual cultural identity. Journal of Marketing Management, 33(9-10), 789-816. doi: $10.1080 / 0267257 X .2017 .1324896$

Elo, M., Minto-Coy, I., Silva, S. C. E., \& Zhang, X. (2020). Diaspora networks in international marketing: How do ethnic products diffuse to foreign markets? European Journal of International Management, 14(4), 693-729. doi: 10.1504/EJIM.2020.107606

Fischer, R., Vauclair, C. M., Fontaine, J. R., \& Schwartz, S. H. (2010). Are individual-level and country-level value structures different? Testing Hofstede's legacy with the Schwartz Value Survey. Journal of Cross-Cultural Psychology, 41(2), 135-151. doi: $10.1177 / 0022022109354377$

Frank, B., Abulaiti, G., \& Enkawa, T. (2012). What characterizes Chinese consumer behavior? A cross-industry analysis of the Chinese diaspora in Japan. Marketing Letters, 23(3), 683-70. doi: 10.1007/s11002-012-9171-8

Ghemawat, P. (2001). Distance still matters : The Hard Reality of Global Expansion. Harvard Business Review, 79(8), 137147. Retrieve from: https://hbr.org/2001/09/distance-stillmatters-the-hard-reality-of-global-expansion

Gliner, J. A., Morgan, G. A., \& Leech, N. L. (2011). Research methods in applied settings: An integrated approach to design and analysis. ( $3^{\text {rd }}$ ed). New York, NY: Routledge. https://doi. org/10.4324/9781315723082

Guzmán, F., Paswan, A. K., \& Fabrize, R. O. (2017). Crossing the border: Changes in self and brands. Journal of Consumer Marketing, 34(4), 306-318. doi: 10.1108/JCM-07-2015-1483

Heinberg, M., Katsikeas, C. S., Ozkaya, H. E., \& Taube, M. (2019). How nostalgic brand positioning shapes brand equity: Differences between emerging and developed markets. Journal of the Academy of Marketing Science, 48(5), 869-890. doi: 10.1007/s11747-019-00637-x

Henthorne, T. L., Williams, A. J., \& George, B. P. (2018). Cross cultural consumer complaining behavior in service industries: A three-nation study across the African diaspora. Journal of Marketing Theory and Practice, 26(4), 431-446. doi: 10.1080/10696679.2018.1488220

Hofstede, G. (2019). The 6 dimensions of national culture. Retrieved from https://www.hofstede-insights.com/models/ national-culture

Holak, S. L. (2014). From Brighton beach to blogs: Exploring food-related nostalgia in the Russian diaspora. Consumption Markets \& Culture, 17(2), 185-207. doi: 10.1080/10253866.2013.776308 
Imbens, G. W., \& Rubin, D. B. (2015). Causal inference in statistics, social, and biomedical Sciences. New York, NY: Cambridge University Press.

Kim, Y., \& Chen, S. (2016). Designing cultural products for AsianAmerican consumers: A conceptual framework. Journal of Cultural Marketing Strategy, 2(1), 51-58. Retrieved from: https://www.researchgate.net/publication/308520884 Designing_Cultural_Products_for_Asian-American_ Consumers_A_Conceptual_Framework

Kogut, B., \& Singh, H. (1988). The effect of national culture on the choice of entry mode. Journal of International Business Studies, 19(3), 411-432. doi: 10.1057/palgrave.jibs.8490394

Krautz, C., \& Hoffmann, S. (2017). The tenure-based customer retention model: A cross-cultural validation. Journal of International Marketing, 25(3), 83-106. doi: 10.1509/ jim.16.0040

Kumar, V., \& Pansari, A. (2016). National culture, economy, and customer lifetime value: Assessing the relative impact of the drivers of customer lifetime value for a global retailer. Journal of International Marketing, 24(1), 1-21. doi: 10.1509/ jim.15.0112

Kumar, N., \& Steenkamp, J. B. E. (2013). Diaspora marketing. Harvard Business Review, 91(10), 127-131. Retrieved from: https://hbr.org/2013/10/diaspora-marketing

Leonidou, L. C., Kvasova, O., Christodoulides, P., \& Tokar, S. (2019). Personality traits, consumer animosity, and foreign product avoidance: The moderating role of individual cultural characteristics. Journal of International Marketing, 27(2), 7696. doi: $10.1177 / 1069031 X_{19834936}$

Liberman, N., Trope, Y., \& Wakslak, C. (2007). Construal level theory and consumer behavior. Journal of Consumer Psychology, 17(2), 113-117. doi: 10.1016/S1057-7408(07)700177

Liviatan, I., Trope, Y., \& Liberman, N. (2008). Interpersonal similarity as a social distance dimension: Implications for perceptions of others' actions. Journal of Experimental Social Psychology, 44(5), 1256-1269. doi: 10.1016/j. jesp.2008.04.007

Matejowsky, T. (2020). What's all the buzz about? Jollibee, diaspora marketing, and next-stage fast food globalization. Food and Foodways, 28(4), 274-296. doi: 10.1080/07409710.2020.1826717

Morgan, N., Pritchard, A., \& Pride, R. (2003). Marketing to the Welsh diaspora: The appeal to hiraeth and homecoming. Journal of Vacation Marketing, 9(1), 69-80. doi: 10.1177/135676670200900105

Mostafa, M. M. (2018). Mining and mapping halal food consumers: A geo-located Twitter opinion polarity analysis. Journal of Food Products Marketing, 24(7), 858-879. doi: 10.1080/10454446.2017.1418695

Murdy, S., Alexander, M., \& Bryce, D. (2018). What pulls ancestral tourists 'home'? An analysis of ancestral tourist motivations. Tourism Management, 64, 13-19. doi: 10.1016/j. tourman.2017.07.011
Ogunyemi, O. (2018). Shaping the perception of African conflicts through framing: A case study of the African diasporic press in the UK. Media, War \& Conflict, 11(4), 421-433. doi: $10.1177 / 1750635218779918$

Oxford Dictionary (n.d.). Definition of nostalgia. Retrieved from https://www.lexico.com/en/definition/nostalgia

Palomino-Tamayo, W., Timana, J., \& Cerviño, J. (2020). The firm value and marketing intensity decision in conditions of financial constraint: A comparative study of the United States and Latin America. Journal of International Marketing, 28(3), 21-39. doi: 10.1177/1069031X20943533

Papadopoulos, N., Banna, A. E., \& Murphy, S. A. (2017). Old country passions: An international examination of country image, animosity, and affinity among ethnic consumers. Journal of International Marketing, 25(3), 61-82. doi: 10.1509/ jim.16.0077

Penaloza, L. (1994). Atravesando fronteras/border crossings: A critical ethnographic exploration of the consumer acculturation of Mexican immigrants. Journal of Consumer Research, 21(1), 32-54. doi: 10.1086/209381

Preez, E. A. du, \& Govender, L. K. (2020). Travelling to the Motherland: Relating acculturation to diaspora tourism experiences. Anatolia, 31(2), 197-210. https://doi.org/10.108 o/13032917.2020.1747220

Quinn, M., \& Devasagayam, R. (2005). Building brand community among ethnic diaspora in the USA: Strategic implications for marketers. Journal of Brand Management, 13(2), 101-114. doi: 10.1057/palgrave.bm.2540251

R4V. (2019). Coordination platform for refugees and migrants from Venezuela. Retrieved from https://ruv.info/en/ situations/platform

Reece, A. G., \& Danforth, C. M. (2017). Instagram photos reveal predictive markers of depression. EPJ Data Science, 6(1), 1-12. doi: 10.1140/epjds/s13688-017-0110-Z

Rosario, A. B., Sotgiu, F., Valck, K. De, \& Bijmolt, T. H. (2016). The effect of electronic word of mouth on sales: A meta-analytic review of platform, product, and metric factors. Journal of Marketing Research, 53(3), 297-318. doi: 10.1509/jmr.14.0380

Schmeichel, M., Kerr, S., \& Linder, C. (2020). Selfies as postfeminist pedagogy: The production of traditional femininity in the US South. Gender and Education, 32(3), 363381. doi: 10.1080/09540253.2017.1411890

Talay, M. B., Akdeniz, M. B., Obal, M., \& Townsend, J. D. (2019). Stock market reactions to new product launches in international markets: The moderating role of culture. Journal of International Marketing, 27(4), 1-18. doi: 10.1177/1069031X19874789

Talay, M. B., Townsend, J. D., \& Yeniyurt, S. (2015). Global brand architecture position and market-based performance: The moderating role of culture. Journal of International Marketing, 23(2), 55-72. doi: 10.1509/jim.13.0164 
Tambiah, S. J. (2017). Transnational movements, diaspora, and multiple modernities. Daedalus, 129(1), 163-194. Retrieved from http://www.jstor.org/stable/20027619

Tien, C., \& Luan, C. J. (2015). Is the magic of the diaspora fact or fiction? A study of Taiwan's trade performance in the bamboo network. Emerging Markets Finance and Trade, 51(sup1), S234-S250. doi: 10.1080/1540496X.2014.998890

Trope, Y., Liberman, N., \& Wakslak, C. (2007). Construal levels and psychological distance: Effects on representation, prediction, evaluation, and behavior. Journal of Consumer Psychology, 17(2), 83-95. doi: 10.1016/S1057-7408(07)70013-X

Vassolo, R. S., Castro, J. O. De, \& Gomez-Mejia, L. R. (2011). Managing in Latin America: Common issues and a research agenda. Academy of Management Perspectives, 25(4), 22-36. https://doi.org/10.5465/amp.2011.0129

Vidal, E. M., \& Tjaden, J. D. (Eds.) (2018). Global migration indicators. Global Migration Data Analysis Centre (GMDAC) International Organization for Migration. Retrieved from https://publications.iom.int/system/files/pdf/global_ migration_indicators_2018.pdf
Vries, L. De, Gensler, S., \& Leeflang, P. S. H. (2012). Popularity of brand posts on brand fan pages: An investigation of the effects of social media marketing. Journal of Interactive Marketing, 26(2), 83-91. doi: 10.1016/j.intmar.2012.01.003

Wagner, K. (2018). Nostalgic photographs in the contemporary image ecology: The example of Tyrrells crisp packaging. Journal of Aesthetics \& Culture, 10(1), 1-12 doi: 10.1080/20004214.2017.1421375

Weaver, D. B., Kwek, A., \& Wang, Y. (2017). Cultural connectedness and visitor segmentation in diaspora Chinese tourism. Tourism Management, 63, 302-314. doi: 10.1016/j. tourman.2017.06.028

Yousaf, S., \& Samreen, N. (2016). Information agents and cultural differences as determinants of country's reputation and its subsequent effects on tourism prospects of a country in sustained crises: The case of Pakistan. Journal of Vacation Marketing, 22(4), 365-384. doi: 10.1177/1356766715623828

Zhao, F., Sun, J., Devasagayam, R., \& Clendenen, G. (2018). Effects of culture and financial literacy among Chinese-Americans on participating in financial services. Journal of Financial Services Marketing, 23(1), 62-75. doi: 10.1057/s41264-018-0044-y

\section{CONTRIBUIÇÃO DE AUTORIA}

Walter Palomino-Tamayo, Maria Christina Saksanian e Otto Regalado-Pezúa declaram que participaram de todas as etapas de desenvolvimento do manuscrito. Dr. Walter Palomino-Tamayo trabalhou na conceituação e abordagem teórico-metodológica. A revisão teórica foi realizada pela Dra. Maria Christina Saksanian. A coleta de dados foi coordenada pelo Dr. Otto Regalado-Pezúa. A análise dos dados incluiu o Dr. Walter PalominoTamayo. Walter Palomino-Tamayo, Maria Christina Saksanian e Otto Regalado-Pezúa trabalharam juntos na redação e revisão final do manuscrito. 